\title{
Influence of Te layer on CdTe thin films and their performance on CdS/CdTe solar cells
}

\author{
C. Hernández-Vásquez*, M.A. González-Trujillo \\ Instituto Politécnico Nacional - ESCOM, Formación Básica, U.P.A.L.M. \\ Gustavo A. Madero, CDMX, 07738, México.
}

\author{
L.A. Esquivel Méndez, J. Aguilar-Hernández, M.L. Albor-Aguilera\# \\ Instituto Politécnico Nacional-ESFM, Depto. de Física, U.P.A.L.M. \\ Gustavo A. Madero, CDMX, 07738, México.
}

(Received: November 11th, 2020; Accepted: September 10th, 2021)

\begin{abstract}
CdTe semiconductor is an absorbent material used in "tandem" photovoltaic solar cells. This material is commonly deposited by thermal evaporation presenting electrical resistivity values about of $10^{5} \Omega \cdot \mathrm{cm}$ to $10^{9} \Omega \cdot \mathrm{cm}$. CdTe is applied in thin solar cells as p-type layer which is in contact with metal back electrode in solar cells. In the CdTe/metal junction a Schottky barrier exits; and small number of charge carriers have enough energy to get over the barrier and cross to the metal back contact. To solve part of this problem, nanostructured Te thin films were used as intermediate layers between CdTe and metal contact. Te layers whit different physical properties were deposited on CdS/CdTe structure by thermal evaporation employing different growth parameters. The electrical parameters of CdTe solar cells were influenced by $\mathrm{p}+$ Te regions. $\mathrm{p}+\mathrm{Te}$ regions used as intermediate layer with large deposition time increases the FF and Voc values from $30 \%$ to $60 \%$ and $560 \mathrm{mV}$ to $730 \mathrm{mV}$ respectively. Also, the electrical resistivity is reduced from $10^{6} \Omega \cdot \mathrm{cm}$ to $10^{3} \Omega \cdot \mathrm{cm}$. In this sense, Te region implemented as nanostructure allows to reduce the series resistance from $99 \Omega$ to $20 \Omega$ and increases the shunt resistance from $1445 \Omega$ to $4424 \Omega$; Te region as thin films demonstrated not be adequate.
\end{abstract}

\section{Introduction}

$\mathrm{CdTe} /$ metal junction and their performance on $\mathrm{CdS} / \mathrm{CdTe}$ solar cells has been studied since a long time ago. A lot of researchers found different difficulties that must be solved for reaching high photovoltaic conversion efficiency near to $22.1 \% \pm 0.5$ [1]. One of the most common problems are back contacts, due to, this technology use copper as part of metallic contact. $\mathrm{Cu}$ diffuses into $\mathrm{CdTe}$ solar cell, producing a short circuit into the device. To solve this effect, different materials have been used, such as $\mathrm{Sb}_{2} \mathrm{Te}_{3}, \mathrm{ZnTe}, \mathrm{ZnTe}: \mathrm{Cu}$ [2-4], these materials passivate the CdTe surface and reduce the Schottky barriers in the semiconductor/metal junction. However, these materials limit carriers transport to the metallic contacts creating recombination centers in $\mathrm{CdTe} /$ Semiconductor/Metal resulting in a diminishing short circuit current density. A common approach to lowering the contact resistance is to create a high work function Te or Terich buffer layer on the CdTe surface prior to the deposition of the metallic back electrode could help in this task. Te is a p-type semiconductor that exhibits high conductivity depending on atomic alignment; its conductivity increases when exposed to light, it can be doped with copper, gold or silver and has a hexagonal structure. This material has been deposited as thin films by techniques as Chemical Vapour Deposition (CVD) [5], Electrochemical Reduction [6] and RF Sputtering [7]. In photovoltaic solar cells, Te as buffer layer allows to reduce the energy potential barrier for hole transport.

On the other hand, to passivate the surface of the CdTe, chemical etchings have been used; chemical solutions of bromo-methanol or Nitric-Phosphoric Acid (NP) are employed [8]. This type of treatment has been found to be effective in the production of a Te rich buffer film, achieving good ohmic contacts with common metals such as Nickel (Ni) or Gold $(\mathrm{Au})$ used as back contacts. However, this chemical etching is a dangerous process no adequate to be implemented in the industrial process.

In this sense, to be friendlier with the environment, other methods must be implemented to reduce the Schottky potential barrier between $\mathrm{CdTe} /$ metal junction. The aim of this work is create a $\mathrm{p}+\mathrm{Te}$ region on CdTe surface in a $\mathrm{CdS} / \mathrm{CdTe} / \mathrm{Cu} / \mathrm{Au}$ photovoltaic device to improve electrical properties in $\mathrm{CdTe} /$ metal junction. Te region was deposited on the CdTe surface using the CSVT (close Space Vapor Transport) technique to passivate the CdTe surface generating a stable and ohmic back contact without chemical etching. Physical properties of Te regions were studied, and CdTe solar with different Te regions as part of the back contact were developed and studied.

\section{Materials and Methods}

A typical superstrate structure solar cells were used to study Te region on $\mathrm{CdTe}$ as part of the back contact in photovoltaic devices. CdTe solar cells were fabricated using Pilkington ${ }^{\circledR}$ glass with a $\mathrm{SnO}_{2}: \mathrm{F}$ thin film around $250 \mathrm{~nm}$ of thickness as substrate, $\mathrm{CdS}$ thin layer as window material and CdTe as absorbent material. CdS films were deposited by chemical bath deposition (CBD) technique with thickness about $60 \mathrm{~nm}$ with an optical transmittance of $90 \%$ and a band gap value of $2.45 \mathrm{eV}[9,10]$. CdTe absorbent material was deposited on CdS thin films by CSVT (Close Space Vapor Transport) technique under argon and oxygen atmospheres at $1 \mathrm{mTorr}$ to create $\mathrm{p}-\mathrm{n}$ junction; Figure 1a shows the CSVT system it is consisting by two principal graphite blocks, substrate and source respectively. Between the blocks exists a graphite container $\mathrm{A}$, where CdTe powder is placed and 


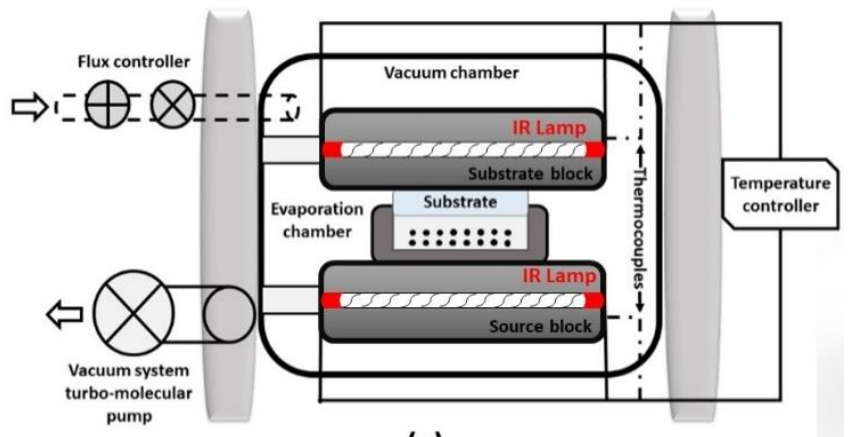

(a)
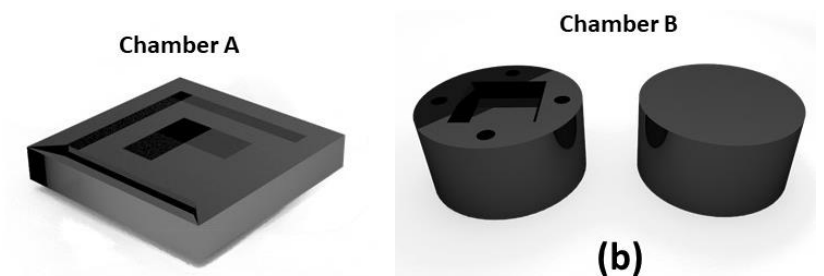

(b)

Figure 1. (a) Schematic of close space vapor transport (CSVT) system and (b) graphite containers.

posteriorly evaporated by using source and substrate temperatures of $630{ }^{\circ} \mathrm{C}$ and $530{ }^{\circ} \mathrm{C}$ respectively for each block during the sublimation process. CdTe thickness layer about $4 \mu \mathrm{m}$ was obtained [11]. The $\mathrm{CdS} / \mathrm{CdTe}$ junction was thermally treated on $\mathrm{CdCl}_{2}$ at $450{ }^{\circ} \mathrm{C}$ by $30 \mathrm{~min}$ in $\mathrm{Ar}$ atmosphere. For simplicity the $\mathrm{CdS} / \mathrm{CdTe}$ samples thermally treated on $\mathrm{CdCl}_{2}$ will be named as CdTe. A Te region was deposited on this samples by using two graphite chambers (A and $\mathrm{B}$ ) with deposition times of $20 \mathrm{~min}$ and $30 \mathrm{~min}$. It is well known that CdTe has a density of $5.85 \mathrm{~g} / \mathrm{cm}^{3}$ and a melting point of $1092{ }^{\circ} \mathrm{C}$ and Te has a density of $6.24 \mathrm{~g} / \mathrm{cm}^{3}$ and a melting point of $449.5^{\circ} \mathrm{C}$; for this reason, it is important to evaporate $\mathrm{Te}$ on the $\mathrm{CdTe}$ at temperatures no higher than its melting point. On the other hand, Te thin film on CdTe surface must be ultrathin since the Te will act as an intermediate layer between $\mathrm{CdTe}$ and metal junction, to improve the Ohmic properties of the semiconductor metal junction. To modify the Te growth kinetics, two types of evaporation graphite containers were designed (A and $\mathrm{B}$ ), see Figure $1 \mathrm{~b}$. The A graphite container (Chamber $\mathrm{A}$ ) is a square container with a depth of $3 \mathrm{~mm}$ and $\mathrm{B}$ container (Chamber B) is a container with small holes with a depth of $8 \mathrm{~mm}$ where the Te powder is placed. The CdS/CdTe junction is placed in chamber A or B; for the last case, the CdS/CdTe samples were placed inside the chamber and samples were enclosed by a graphite cap, leaving a closed chamber. The chamber A or B are placed between the source and substrate blocks allowing control rate deposition to get a nanostructured region on $\mathrm{CdS} / \mathrm{CdTe}$ surface. Finally, $\mathrm{Cu}$ $(5 \mathrm{~nm})$ and $\mathrm{Au}(100 \mathrm{~nm})$ metals were evaporated to conform the metal back contact.

The polycrystalline structures of the samples were measured by X-ray diffraction (XRD), X'PERT Pro MRD PANalytical X-ray system using the $\mathrm{Cu}-\mathrm{K} \alpha$ line, morphological surface and EDS elemental analysis was made with a scanning electron microscope (SEM) JEOL series JSM7X using high accelerating voltage $(5 \mathrm{kV})$. A step profiler Sloan Dektak II was employed to obtain thickness layers. Morphological measurements were performed with an Innova Veco AFM in contact mode, using a phosphorus doped $\mathrm{Si}$ tip. Optoelectronic behavior was studied by photoluminescence (PL) measurements at $14 \mathrm{~K}$ using a He$\mathrm{Cd}(325 \mathrm{~nm})$ source. To measure electrical properties a Keithley 6517B electrometer/high resistance meter was used, and electrical sheet resistance values was obtained from four-point probe measurements. How is well known, the units of ohms per square by forcing current trough two outer probes and reading the voltage across the two inner probes, this configuration avoids error due to contact resistance between probe and sample. Band gap values of $\mathrm{CdTe}$ and $\mathrm{CdTe} / \mathrm{Te}$ were obtained by photoacoustic spectroscopy technique, a Corner Stone C130 grating monochromator coupled to Xenon lamp (1000 W) as light source were used; the light was modulated at fixed frequency using a New Focus 3502 Phase Locked Optical Chopper. An electret microphone coupled to close photoacoustic cell is used to detect the photoacoustic signal (amplitude and phase) using a Stanford Research SR850 lock-in amplifier. Photovoltaic efficiency (PV) was performed by Sol3A Class AAA Solar simulator equipment with a light source of $100 \mathrm{~mW} / \mathrm{cm}^{2}$ (AM1.5), the electrode area is $0.08 \mathrm{~cm}^{2}$.

\section{Results and discussion}

In Table 1 the growth parameters for all samples are presented. Different Te morphologies were obtained as a function of the specific graphite container (A or B) used. $\mathrm{CdS} / \mathrm{CdTe}$ junction thermally treated on $\mathrm{CdCl}_{2}$ is named as $\mathrm{CdTe}$. The reported thickness corresponds to complete structure $(\mathrm{CdS} / \mathrm{CdTe})$ and Te layer. Samples were named according with the specific chamber used and deposit time. Some samples with Te layer were thermally treated in air (TT) at $400^{\circ} \mathrm{C}$ for $30 \mathrm{~min}$.

Figure 2 shows SEM images of CdTe thin films thermally treated with $\mathrm{CdCl}_{2}$ and Te structures covering CdTe samples. CdTe sample is formed by well-defined grains with mean

Table 1. Growth parameter of $\mathrm{CdTe}$ and $\mathrm{CdTe} / \mathrm{Te}$ samples

\begin{tabular}{|c|c|c|c|c|c|c|}
\hline Samples & 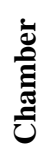 & 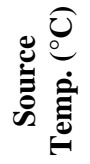 & 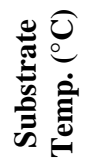 & 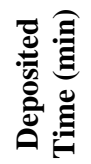 & 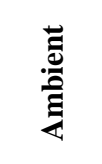 & 总 \\
\hline $\mathrm{CdTe}$ & A & 630 & 530 & 3 & $\mathrm{CdCl}_{2}$ & 4 \\
\hline Te20A & A & 450 & 225 & 20 & - & 4.73 \\
\hline Te20Aтт & A & 450 & 225 & 20 & Air & 4.5 \\
\hline Te30A & A & 450 & 225 & 30 & - & 5.6 \\
\hline Te $30 A_{\text {TT }}$ & A & 450 & 225 & 30 & Air & 4.46 \\
\hline Te30B & $\mathrm{B}$ & 400 & 225 & 30 & - & 4.7 \\
\hline $\mathrm{Te} 30 \mathrm{~B}_{\mathrm{TT}}$ & $\mathrm{B}$ & 400 & 225 & 30 & Air & 4.7 \\
\hline
\end{tabular}




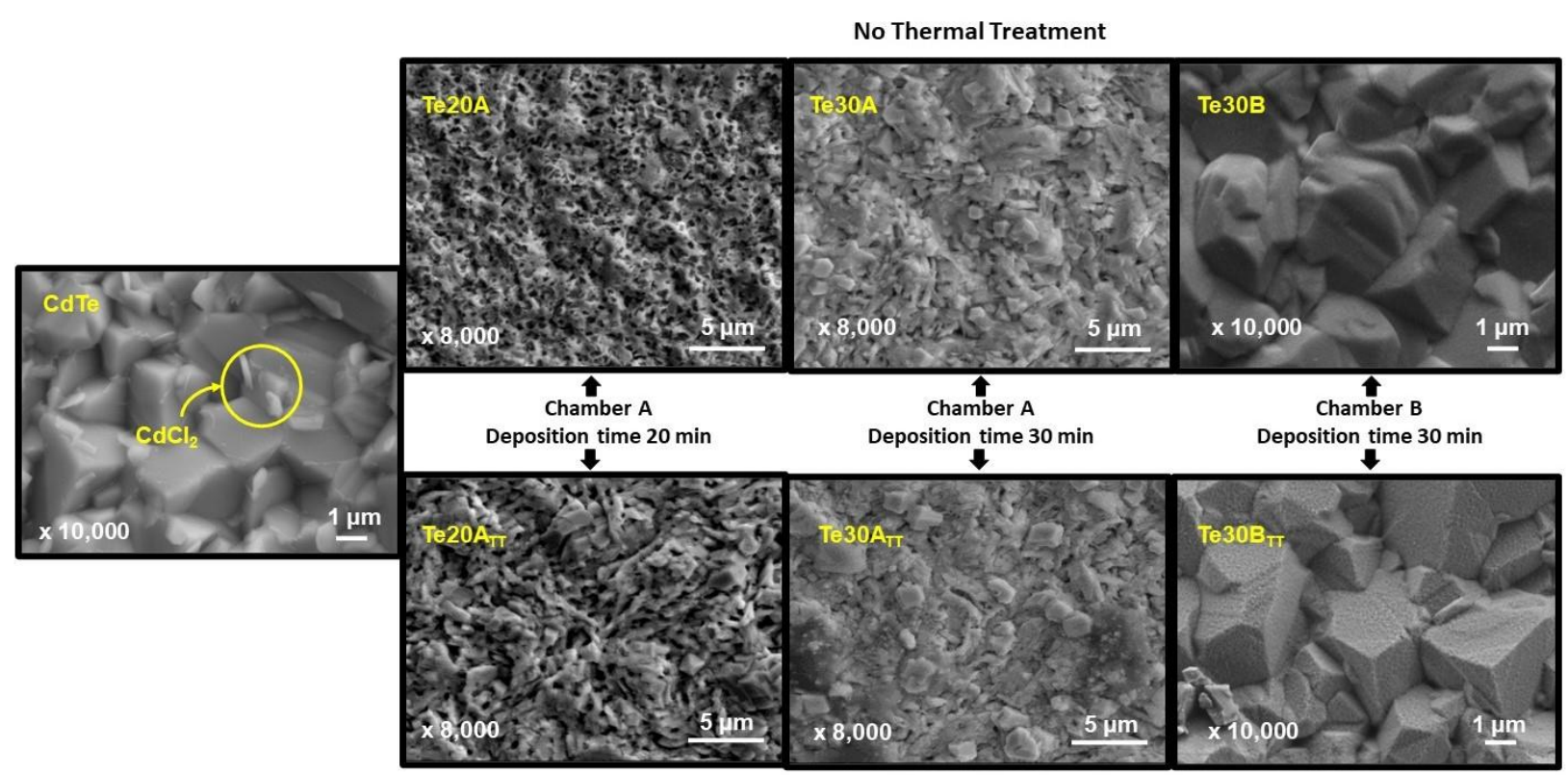

Thermal Treatment

Figure 2. SEM images at $5 \mathrm{kV}$ of CdTe thin film and Te structures covering CdTe surface.

sizes about 4-5 $\mu \mathrm{m}$; small grains appear on its surface corresponding to $\mathrm{CdCl}_{2}$ grains. Te20A, Te30A and Te30B exhibit a covered surface with different morphologies, the first one corresponds to Te agglomerates, the second one shows defined grains along the sample; in both cases Te structures could be seen as a thin film. On the other hand, Te30B sample is covered by uniform Te nano structures. Te $20 \mathrm{~A}_{\mathrm{TT}}, \mathrm{Te} 30 \mathrm{~A}_{\mathrm{TT}}$ and $\mathrm{Te} 30 \mathrm{~B}_{\mathrm{TT}}$ were thermally treated in air, this treatment modified their morphology leading grains more defined and largest. A better defined Te nanostructured layer appears covering uniformly the surface of $\mathrm{Te} 30 \mathrm{~B}_{\mathrm{TT}}$ sample. It is important to remark that two different $\mathrm{Te}$

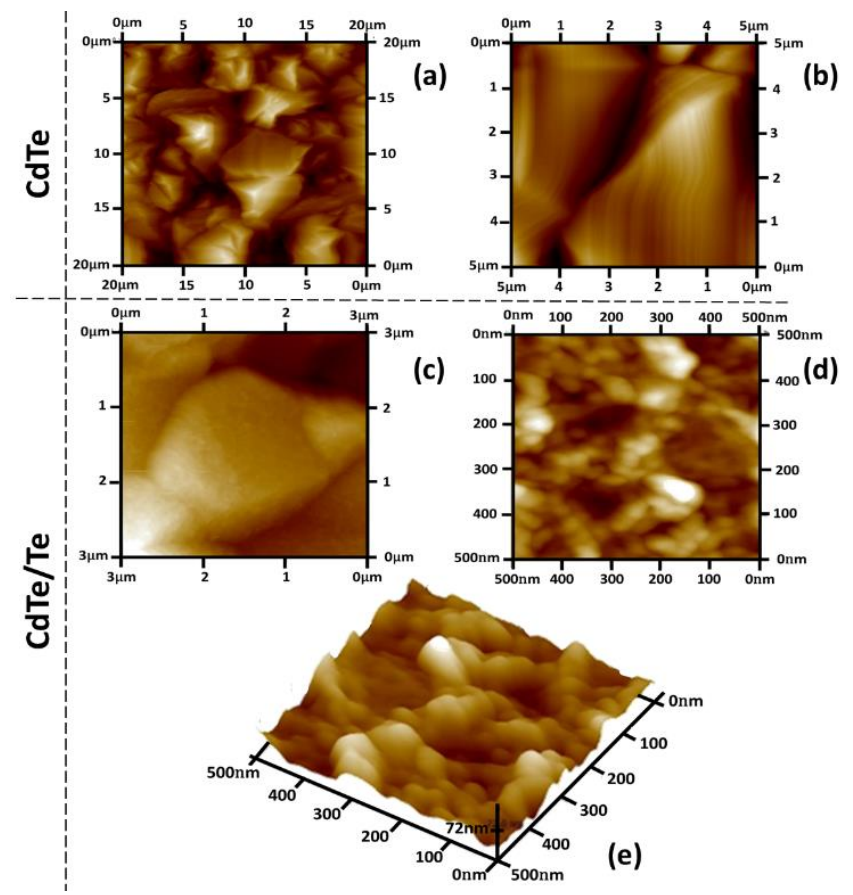

Figure 3. AFM images for CdTe and CdTe/Te samples structures were obtained one of them as a thick layer and another as nanostructured layer. These morphological properties could be important on the semiconductor/metal junction due to it could improve the electrical properties.

Figure 3 shows the AFM images of CdTe and CdTe covered with Te nanostructures (Te30BTT). Figures $3 \mathrm{a}$ and $3 \mathrm{~b}$ show CdTe grains at different scale where well-defined grains are observed. Figure $3 \mathrm{c}$ shows $\mathrm{CdTe}$ grains covered with $\mathrm{Te}$ and $\mathrm{Te}$ nanostructure can be seen with a better definition in Figs $3 \mathrm{~d}$ and $3 \mathrm{e}$, with this nanostructure a potential barrier between CdTe and Metal is reduced increasing the efficiency of this junction.

According to the SEM results, the thermally treated samples are appropriated to continue with the analysis due to a uniform Te structure is required to be applied on photovoltaic devices. In this sense, elemental analysis (EDS) and electrical measurements, only for these samples are presented in Figure 4. Cd and Te percent content are shown in Figure 4a for each sample; the $\mathrm{Cd}$ and $\mathrm{Te}$ content for $\mathrm{CdTe}$ sample are $46 \%$ and $54 \%$ respectively. The deposit time affects the kinetic growth for Te layer (see Figure 2), For Te $20 \mathrm{~A}_{\mathrm{TT}}$ and $\mathrm{Te} 30 \mathrm{~A}_{\mathrm{TT}}$, Te quantity diminish on the other hand this quantity increases for $\mathrm{Te} 30 \mathrm{~B}_{\mathrm{TT}}$ (see Fig, 4a). Figure $4 \mathrm{~b}$ shows electrical properties of samples. The electrical sheet resistance values were measured from four-point probe method. Resistivity values for CdTe are reported around $10^{5} \Omega \cdot \mathrm{cm}$ [12]. All CdTe samples covered with Te showed resistivity values of $10^{3} \Omega \cdot \mathrm{cm}$. The last results are important because the semiconductor/metal junction could be improved in electrical properties; a better Ohmic contact is probably to be obtained in this junction.

Considering the morphological and electrical properties of all samples, Te $30 \mathrm{~B}_{\mathrm{TT}}$ has adequate properties until now to be applied on photovoltaic devices. Figure 5 shows the X-ray diffraction (XRD) patterns of CdTe and $\mathrm{Te} 30 \mathrm{~B}_{\mathrm{TT}}$; however, due to the electrical properties of the Te $30 \mathrm{~A}_{\mathrm{TT}}$ sample is 
(a)

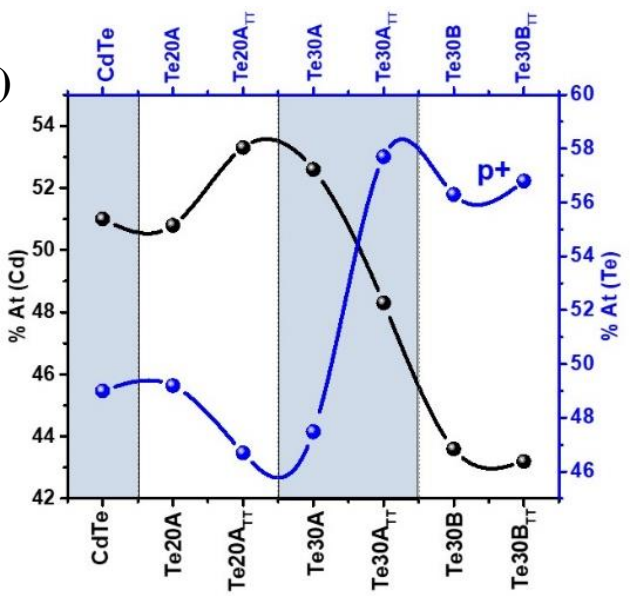

(b)

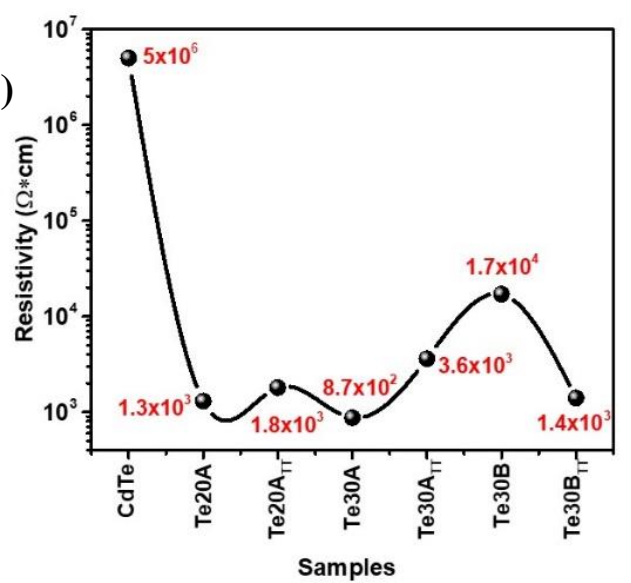

Figure 4. (a) Elemental analysis (EDS) to CdTe and CdTe covered with different Te structures and (b) Resistivity values for samples.

included in the XRD spectra. Cubic-CdTe and hexagonal-Te theoretical structures are identified using PDF\# 15-0770, and PDF\# 36-1452 respectively. A Te crystalline structure is confirmed by XRD patterns, Te30A $\mathrm{A}_{\mathrm{TT}}$ sample shows strong diffraction peaks at $27.5^{\circ}, 38.8^{\circ}$, and $46^{\circ}$ corresponding to (101), (102), (003) crystalline planes. For Te30B $\mathrm{B}_{\mathrm{TT}}$ sample, a principal peak is located at $23.7^{\circ}$ corresponding with (111) diffraction plane, indicating greater crystallinity.

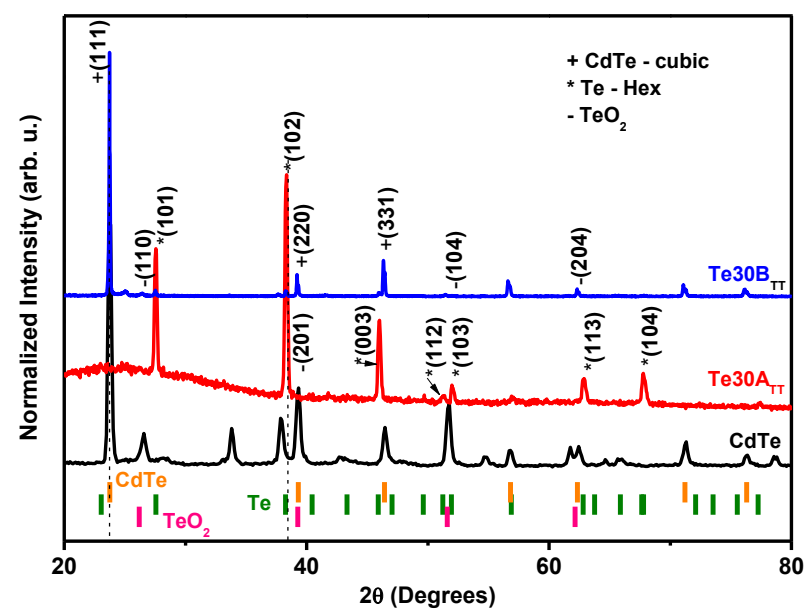

Figure 5. XRD difractograms of CdTe and CdTe covered with a Te layer and a nanostructured Te layer.

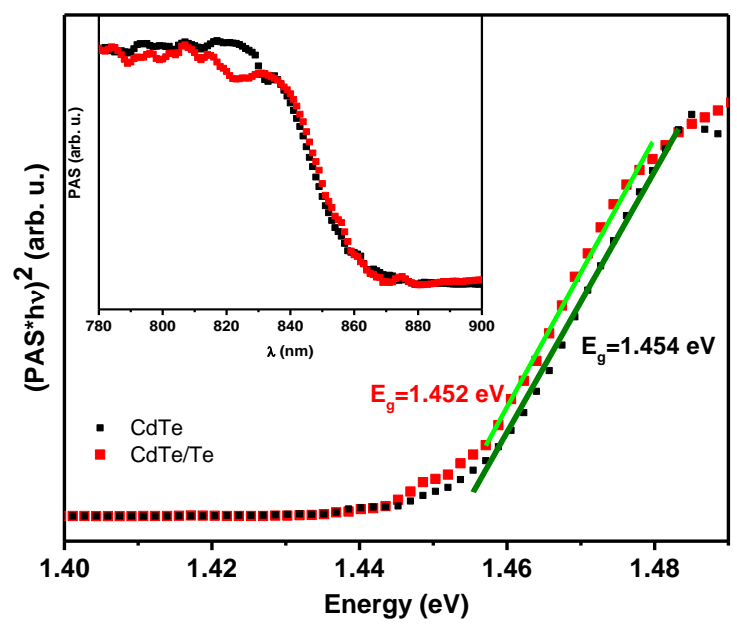

Figure 6. Thermal signal extrapolation and PAS spectra of CdTe and $\mathrm{CdTe} / \mathrm{Te}$.

In order to determine the band gap value of all samples, photoacoustic spectroscopy (PAS) was performed. The mathematical model to describe the photoacoustic effect is determined using heat and continuity equations in which heat source is included as a result of the modulated light absorption; PAS signal is obtained as a function of photon energy, in this case the light excitation modulation fixed at $18 \mathrm{~Hz}$, considering these ideas the optical absorption $(\alpha)$ in the equation (1) can be considered proportional to PAS signal [13, 14],

$$
(\alpha \cdot h v)^{n}=A\left(E_{g}-h v\right)
$$

The linear extrapolation of $(P A S \cdot h v)^{2} v S(h v)$ in the experimental plot obtained by thermal technique allows to determine $\mathrm{E}_{\mathrm{g}}$ values. Figure 6 shows the band gap calculations of samples obtained from PAS spectra (see inset in figure 6). The CdTe band gap is around $1.454 \mathrm{eV}$ $\pm 0.002 \mathrm{eV}$ that correspond with reported values [15]. For all $\mathrm{CdTe} / \mathrm{Te}$ a similar band gap values $(1.452 \pm 0.002 \mathrm{eV})$ were obtained; only a representative $\mathrm{CdTe} / \mathrm{Te}$ spectrum is included in Figure 6.

Optoelectronic properties of materials have received considerable attention due to their application in photovoltaic devices, in this sense photoluminescence (PL) measurements were made. Figure 7 shows the PL spectra of CdTe, Te30A $\mathrm{A}_{\text {Tт }}$ and Te30B $\mathrm{B}_{\mathrm{TT}}$ samples. The PL spectra show three main energy bands located at $1.59 \mathrm{eV}, 1.55 \mathrm{eV}$ and $1.44 \mathrm{eV}$. Authors have identified an excitonic emission around $1.59 \mathrm{eV}[16,17]$, the band located at $1.4 \mathrm{eV}$ related to cadmium vacancy-choline complex. The range between $1.40 \mathrm{eV}$ to $1.50 \mathrm{eV}$ is commonly associated with $\mathrm{CdTe}$ structure defects. Some band energy values $(1.437 \mathrm{eV}$, $1.440 \mathrm{eV}, 1.459 \mathrm{eV}, 1.465 \mathrm{eV}$ and $1.478 \mathrm{eV}$ ) in this range are related to $\mathrm{CdS}_{\mathrm{x}} \mathrm{Te}_{1-\mathrm{x}}$ intermixing [18], $\mathrm{V}_{\mathrm{Cd}}-\mathrm{Cl}_{\mathrm{Te}}$ transition, donor-acceptor pair (DAP) transition, $\mathrm{V}_{\mathrm{Cd}}-\mathrm{Cl}_{\mathrm{Te}}$ transition and Y-band (phonon replicas) [19] respectively. The $1.55 \mathrm{eV}$ emission is related with oxygen, the incorporation of this oxygen, it could be located in a Te site as an isoelectronic defect or $\mathrm{TeO}_{2}$ formation. On the other hand, $\mathrm{TeO}_{2}$ phase is corroborated by XRD difractograms (See Figure 5). 


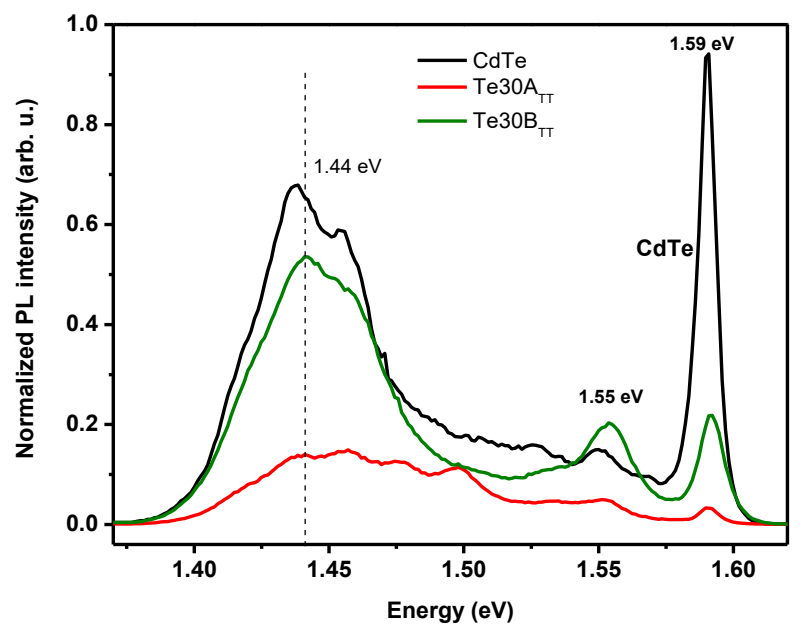

Figure 7. PL spectra of CdTe and CdTe/Te samples under study.

\section{Te structures performance on CdTe solar cells}

$\mathrm{CdTe}$ solar cells were developed by using $\mathrm{CdS}(60 \mathrm{~nm})$ and $\mathrm{CdTe}(4 \mu \mathrm{m})$ as window and absorbent layers; $\mathrm{CdS} / \mathrm{CdTe}$ junction was thermally annealed on $\mathrm{CdCl}_{2}$ and after thermally treated in air. Different Te morphologies on $\mathrm{CdS} / \mathrm{CdTe}$ junctions were deposited; $\mathrm{Cu} / \mathrm{Au}$ was used as metal back contacts with an area of $0.08 \mathrm{~cm}^{2} . \mathrm{Cu}$ is commonly used as back contact due to its efficient electrical properties; different Te layers were deposited on CdTe surface to reduce the $\mathrm{Cu}$ diffusion along the photovoltaic solar cell improving the semiconductor/metal junction. All solar cells (SC) configurations are represented in Figure 8a, each one has a specific Te layer under study SC1:Te20A, SC2:Te20A $\mathrm{SC} 5: \mathrm{Te} 30 \mathrm{~B}_{\text {TT. }}$. Traditional configuration of $\mathrm{CdS} / \mathrm{CdTe}$ photovoltaic device without Te layer was named CdTe. All solar cells were evaluated considering an illuminated area of $0.08 \mathrm{~cm}^{2}$ under global AM 1.5 solar spectra, In table 2 are showed the best result of each solar cell. No antireflection coatings were used.

Figure $8 \mathrm{~b}$ shows the $\mathrm{J}-\mathrm{V}$ electrical behavior for all devices, electrical parameters as short current density $\left(\mathrm{J}_{\mathrm{SC}}\right)$, open

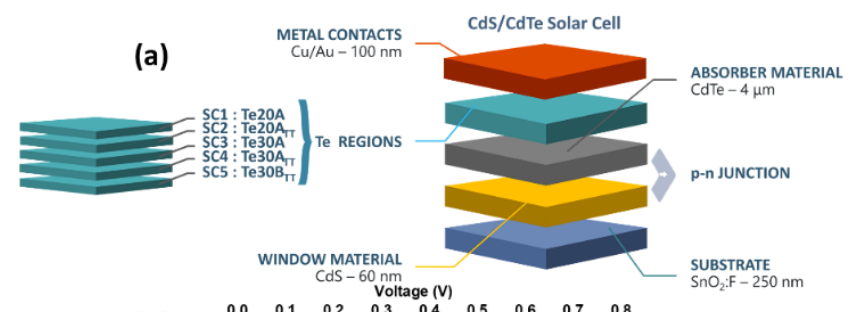

(b)

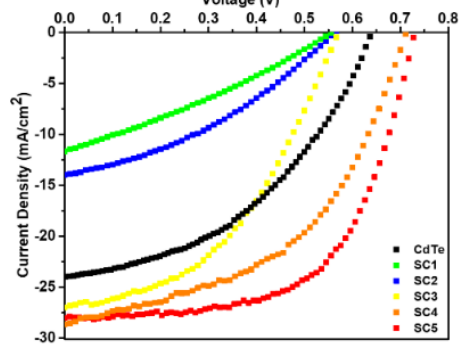

Figure 8. (a) Schematic $\mathrm{CdTe}$ and $\mathrm{CdTe} / \mathrm{Te}$ devices and (b) $\mathrm{J}-\mathrm{V}$ measurements for all photovoltaic devices
Table 2. Electrical parameters of CdTe and CdTe/Te photovoltaic devices.

\begin{tabular}{cccccc}
\hline Devices & $\begin{array}{c}\text { Voc }(\mathbf{m V}) \\
\mathbf{\pm 1} \mathbf{~ m V}\end{array}$ & $\begin{array}{c}\mathbf{J S C}\left(\mathbf{m A} / \mathbf{c m}^{\mathbf{2}}\right) \\
\mathbf{\pm 3 m A} / \mathbf{c m}^{2}\end{array}$ & $\begin{array}{c}\text { FF (\%) } \\
\mathbf{\pm 0 . 6 \%}\end{array}$ & $\boldsymbol{n}$ & $\begin{array}{c}\boldsymbol{\eta}(\boldsymbol{\%}) \\
\mathbf{\pm 0 . 8 \%}\end{array}$ \\
\hline CdTe & 638 & 24 & 43 & 13 & 6.8 \\
SC1 & 560 & 12 & 30 & 14 & 1.4 \\
SC2 & 560 & 14 & 36 & 12.2 & 2 \\
SC3 & 620 & 27 & 51 & 8.6 & 6.1 \\
SC4 & 720 & 28 & 51 & 6.9 & 7.5 \\
SC5 & 730 & 28 & 60 & 5 & 12 \\
\hline
\end{tabular}

circuit voltage $\left(\mathrm{V}_{\mathrm{OC}}\right)$, fill factor $(\mathrm{FF})$ values and photovoltaic efficiency $(\eta)$ are shown in table 2 . These characteristics were influenced by the specific photovoltaic structure and Te morphology. Te layer used as part of the back contact improves the $\mathrm{J}_{\mathrm{SC}}, \mathrm{V}_{\mathrm{OC}}$ and $\mathrm{FF}$ values. Inadequate ideality factor and the photovoltaic efficiency values were obtained when Te as layer is used as part of the back contact in CdTe photovoltaic devices. On the other hand, nanostructured $\mathrm{Te}$ on $\mathrm{CdS} / \mathrm{CdTe}$ junction improves the $\mathrm{V}_{\mathrm{OC}}$ and $\mathrm{FF}$ values due to nanostructures Te helps to create a good depletion region between $\mathrm{CdS} / \mathrm{CdTe}$ junction, and it reduces the recombination mechanism. The photovoltaic efficiency was improved by nanostructure Te used as part of the back contact in CdTe solar cells. Te thicknesses greater than $1 \mu \mathrm{m}$ increase the potential barrier so, the photo generated electrons energy is not enough to cross this potential barrier. The ideality factor diode (n) was determined by Cheung method for each solar cell. Considering this method, the relationship between some electrical parameters at temperature $T$ involving the one diode model is given by:

$$
I=I_{0}\left(e^{\left(\frac{V-I R_{S}}{n k T}\right)}-1\right)+\frac{V-I R_{S}}{R_{S h}}-I_{\text {lig }}
$$

Equation (2) enables the calculation of ideally factor diode $n$, where $k$ is the Boltzmann constant, applied voltage $(V)$, shunt and series resistance $\left(R_{s}, R_{s h}\right)$, and $l_{\text {lig }}$ is light current, when solar cell is under illumination [20].

Series $\left(R_{s}\right)$ and shunt $\left(R_{s h}\right)$ resistance values for all photovoltaic devices are presented in Figure 9. Te thickness

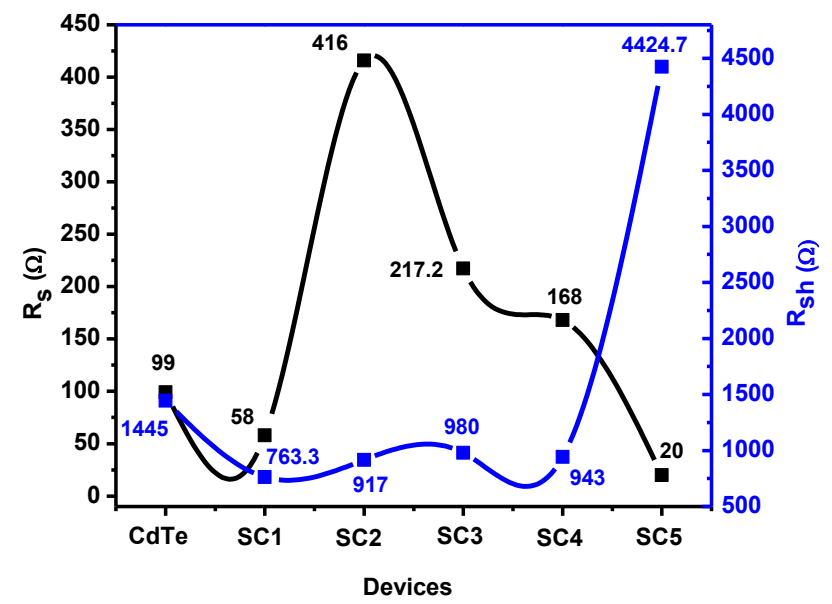

Figure 9. Series and shunt resistance from $\mathrm{CdTe}$ and $\mathrm{CdTe} / \mathrm{Te}$ solar cells. 
modified the series resistance, also in this sense nanostructure Te layer decreases the $R_{S}$ values in photovoltaic devices. Nanostructured Te used in CdTe/metal junction reduces the $R_{S}$ values and thermal treatment in this case improves this value. On the other hand, $R_{s h}$ values increases when nanostructured Te with a thermal process is employed as part of the back contact.

\section{Conclusions}

CdTe photovoltaic solar cells were fabricated, considering Te as a film and as a nanostructure as part of the back contact. Chamber A and B were designed to modified Te growth on CdTe surface, in this way, $\mathrm{p}+\mathrm{Te}$ region was obtained as thick layer and nanostructured Te region respectively. This part is important because it is necessary to create a $\mathrm{p}+\mathrm{Te}$ intermediate layer to improve the electrical properties between $\mathrm{CdTe} /$ metal junction.

A Te uniform region was obtained by using Chamber B, in this case CdTe grains were covered by the $\mathrm{Te}$ as nanostructured region allowing to reduce grain boundaries it means potential barriers reduction leading an easily carries mobility to the back contact. Electrical parameters of CdTe solar cells were improved by using nanostructured Te region as buffer layer, the $\mathrm{FF}$ and $\mathrm{V}_{\mathrm{OC}}$ values varied from $30 \%$ to $60 \%$ and $560 \mathrm{mV}$ to $730 \mathrm{mV}$ respectively. The electrical resisitivity in CdTe was reduced from $10^{6} \Omega \cdot \mathrm{cm}$ to $10^{3} \Omega \cdot \mathrm{cm}$, series and shunt resistance were reduced and increased due to nanostructured Te as buffer layer. A Te thick layer was obtained on CdTe by using Chamber A, in this case the FF and $\mathrm{V}_{\mathrm{OC}}$ values were decreased thus decreasing the photovoltaic efficiency. Therefore, to improve the electrical properties of the semiconductor/metal junction, it is better to use a nanostructured Te region than a film of Te.

\section{Acknowledgements}

The authors gratefully acknowledge projects SIP20210070, SIP-20210068 and CONACYT.

\section{References}

[1] M.A. Green, E.D. Dunlop, J. Hohl-Ebinger, M. Yoshita, N. Kopidakis, A.W.Y. Ho-Baillie, Prog. Photovolt.: Res. Appl. 28, 3 (2020).
[2] R. Mendoza, J. Sastre, A. del Oso, M. de los A. Hernández, J. Lizardi, G. Casados, G. Santana, IJRDO-J. Appl. Sci. 5, 48 (2019). [3] D.I. Kurbatov, V.V. Kosyak, M.M. Kolesnyk, A.S. Opanasyuk, S.N. Danilchenko, Yu.P. Gnatencko, Mater. Chem. Phys. 138, 731 (2013).

[4] A. Bosio, R. Ciprian, A. Lamperti, I. Rago, B.Ressel, G. Rosa, M. Stupar, E. Weschke, Sol. Energy 176, 186 (2018).

[5] Y-T Ma, Z-Q Gong, W-H Xu, J. Huang, Trans. Nonferrous Met. Soc. China 16, 693 (2006).

[6] T. Gabriel, I.S. Nandhakumar, G.S. Attard, Electrochem. Commun. 4, 610 (2002).

[7] T. Siciliano, M. Di Giulio, M. Tepore, E. Filippo, G. Micocci, A. Tepore, Sens. Actuators B Chem. 135, 250 (2008).

[8] X. Li, D.W. Niles, F.S. Hasoon, R.J. Matson, P. Sheldon, J. Vac. Sci. Technol. A 17, 805 (1999).

[9] J.M. Flores Marquez, M.L. Albor Aguilera, Y. Matsumoto Kuwabara, M.A. Gonzalez Trujillo, C. Hernandez Vasquez, R. Mendoza Perez, G.S. Contreras Puente, M. Tufiño Velazquez, Thin Solid Films 582, 124 (2015).

[10] M.L. Albor Aguilera, J.M. Flores Marquez, M.A. Gonzalez Trujillo, C. Hernandez Vasquez, G.S. Contreras Puente, C. Mejia Garcia, G. Rueda Morales, Rev. Mex. Fis. 62, 129, (2016).

[11] C. Hernandez Vasquez, M.L. Albor Aguilera, M.A. Gonzalez Trujillo, J.M. Flores Marquez, U. Galarza Gutierrez, J.R. Aguilar Hernandez, D. Jimenez Olarte, Rev. Mex. Fis. 63, 469, (2017).

[12] N. Spatalu, J. Hiie, V. Valdna, M. Caraman, N. Maticiuc, V. Mikli, T. Ptlog, M. Krunsks, V. Lughi, Energy Procedia 44, 85 (2014).

[13] M.L. Albor-Aguilera, M.A. González-Trujillo, A. Cruz Orea, M. Tufiño-Velazquez, Thin Solid Films 517, 2335 (2009).

[14] U. Galarza-Gutierrez, M.L. Albor-Aguilera, M.A. GonzalezTrujillo, C. Hernandez-Vasquez, J.A. Ortega-Cardenas, J.M. Flores Marquez, F. Cruz-Gandarilla, D. Ramirez-Rosales, R. MendozaPerez, G. Rueda-Morales, J.R. Aguilar-Hernandez, H. YeeMadeira, Mater. Res. Express 6, 125510 (2019).

[15] O. Madelug, Semiconductors Basic Data, 2nd ed. (Berlin, Springer-Verlag, 1996) p. 186.

[16] K. Li, C. Li, G. Chen, S. Ren, W. Gao, L. Wu, J. Zhang, Chalcogenide Lett. 15, 91 (2018).

[17] J. Van Gheluwe, J. Versluys, D. Poelman, P. Clauws, Thin Solid Films 480-481, 264 (2005).

[18] D. Menossi, E. Artegiani, I. Rimmaudo, A. Le Donne, S. Binetti, J.L. Peña, F. Piccinelli, A. Romeo, Conf. Rec. IEEE Photovolt. Spec. Conf. 44th, 1669 (2017).

[19] D.S. Albin, D. Kuciauskas, J. Ma, W.K. Metzger, J.M. Burst, H.R. Moutinho, P.C. Dippo, Appl. Phyis. Lett. 104, 092109 (2014). [20] S.K. Cheung, N.W. Cheung, Appl. Phys. Lett. 49, 85 (1986).

(C) 2021 by the authors; licensee SMCTSM, Mexico. This article is an open access article distributed under the terms and conditions of the Creative Commons Attribution license (http://creativecommons.org/licenses/by/4.0/). 